\title{
Social Security and \\ Intragenerational Redistribution of Lifetime Income in Japan*
}

\author{
Tokyo Gakugei University \\ Takashi Oshio
}

\begin{abstract}
This paper investigates how social security redistributes lifetime income within the same generation in Japan, based on data from the Survey on the Redistribution of Income. The progressivity of Japan's public pension program appears to be much more limited on a lifetime basis than on an annual basis. Given an aging population, replacing the current pay-as-you-go system with a simple one that consists of a flat benefit and a wage-proportional premium, and has no maximum contribution, can be desirable in terms of both efficiency and intragenerational equity. The redistributive effects of income tax and consumption tax to finance the benefit are also examined.
\end{abstract}

JL classification: $\mathrm{H} 55, \mathrm{H} 23$

* This paper was written as a part of the Kosei Rodo Kagaku Kenkyu Hojokin Seisaku Kagaku
Suishin Jigyo: "Project on Social Security System to Meet the Needs of Changing Family and Work
(H14-Seisaku-034)" (2002-2004). The data used in the paper are based on the work of an earlier
project whose results were presented in Oshio (2002). I am grateful to the seminar participants at
the National Institute of Population and Social Security Research for their useful comments. I also
acknowledge financial support from the grants: "the Scientific Researches of Priority Areas 603:
Project on Intergenerational Equity" from the Ministry of Education, Science and Culture, Japan.

Correspondence to: Takashi Oshio, Tokyo Gakugei University, 4-1-1 Nukui Kitamachi, Koganei, Tokyo, 184-8501, tel/fax +81-42-379-7415, t-oshio@mb8.seikyou.ne.jp 


\section{Introduction}

The social security system redistributes income from the young to the old, because it generally has a pay-as-you-go (PAYGO) structure. This redistributive effect, especially of public pension programs, is sometimes assessed from two viewpoints. First, with a rapidly aging population a PAYGO system is likely to entail substantial income transfers across generations and reduce the net lifetime incomes of young and future generations. There have been many attempts to empirically address the issues of intergenerational redistribution and inequality by selecting a representative individual of each generation. Hatta, Oguchi, and Sakamoto (1998) and Takayama and Kitamura (1999) are recent examples of studies from this standpoint in Japan. However, the models of heterogeneous individuals can yield ambiguous results; for instance, the possibility cannot be ruled out that individuals with lower incomes can earn net social security transfers from the government due to the progressive benefit and premium/tax formula, even if the average net income of the generation to which they belong falls under a PAYGO system.

Second, social security is often expected to reduce income inequality on an annual basis, because the old who receive benefits are poorer on average than the young who pay premiums and taxes. Indeed, the Ministry of Health, Labor, and Welfare (2002) emphasized that social security as a whole succeeds in holding down the Gini index, which has been on a clear upward trend in recent years in Japan. However, this type of assessment tends to be misleading, because each individual experiences being young and old in his or her life. Indeed, comparing the data from the 1981 and 1993 Surveys on the Redistribution of Income, Ohtake and Saito (1999) found that while the effects of redistribution policies were brought about mainly by a reduction of differentials within age groups in 1981, the narrowing of income gaps between age groups made a greater contribution in 1993. Based on these results, they 
pointed out the problem of simply linking a reduction of income differentials with an evaluation of redistribution policies. In addition, Teruyama and Ito (1994) decomposed the cross-sectional inequality of income and wealth into intra-age inequality ("true inequality") and inter-age inequality ("apparent inequality"), using an overlapping generations model.

One of the key issues uncovered by these two types of discussion is intragenerational redistribution on a lifetime basis; that is, how social security as a life-cycle program redistributes lifetime income within the same generation. While it is debatable whether or not social security should aim to redistribute income by itself, it is important to capture the magnitude of its ex post redistributive effects in order to design an overall structure of redistribution policies. On a lifetime basis, the benefit and premium/tax formula appears to redistribute income from those who earn more during their working years to those who earn less. This progressivity of the system, however, is naturally expected to be lower than observed on an annual basis, and to be difficult to measure.

In recent years, there have been a growing number of studies in the United States aiming to quantify the lifetime progressivity of the social security system using panel data, and to analyze its sensitivity to family or spousal features, mortality, and other heterogeneous factors. For example, Coronado, Fullerton, and Glass (2000) found that social security is much less progressive on a lifetime basis than on an annual basis, and quantified several individual characteristics that are relevant to determine the progressivity of social security. Gustman and Steinmeier (2001) pointed out that social security looks less progressive if individuals are grouped into households and adjusted for variations in secondary earner's income than it does when looking at retired worker benefits. Liebman (2002) emphasized that spouse benefits and differential mortality can offset a large part of the progressivity provided by the benefit formula. Furthermore, Coronado et al. (2002) conducted micro-simulations to compare the effects of several PAYGO reforms on the overall progressivity of the system. 
In Japan, by contrast, it is very difficult to make a lifetime income-based analysis of intragenerational redistribution, because unlike in the United States, adequate panel data are unavailable. Based on a numerical analysis of a two-period life-cycle model, Shimono and Tachibanaki (1985) determined to what extent public pension programs redistribute lifetime income in Japan. They showed that a flat component of the pension benefits reduces the inequity of lifetime income and that an increase in a wage-proportional premium rate contributes to a reduction of income inequality. Takayama et al. (1990), who estimated the streams of lifetime income using micro-data from the 1994 National Survey on Consumption, first attempted to quantify the redistribution effects of the public pension programs across and within generations in Japan. They found that in older age groups, those with higher incomes receive greater net benefits, pointing to at least a partial regressivity of public pension programs. However, they neglected the "incompleteness" of the system; that is, the fact that social security benefits are covered not only by premiums but also by government subsidies (that are eventually financed by income and other taxes), as well as burdens postponed to future generations.

This paper focuses on Japan's public pension program, especially the Kosei Nenkin program for employed workers in the private sector, and attempts to measure its potential redistributive effects and progressivity on a lifetime basis using data from the 1996 Survey on the Redistribution of Income. Besides measuring the progressivity of the current system, we attempt to estimate the impacts of social security and tax reforms in terms of both efficiency and intragenerational equity in the long run. Due to limited information about each individual's earning's history, our analysis depends on artificially constructed streams of employees' lifetime incomes that are consistent with the actual income distribution on an annual basis shown in the Survey. Our analysis also concentrates on a steady state, in which each generation grows (shrinks) at the same fixed pace, and benefit payments are completely financed by premium 
and/or tax revenues at each time. This type of analysis cannot grasp the dynamics of income transfer across generations nor explicitly address intergenerational equity issues. We believe, however, that it can provide a basic picture of the potential progressivity and redistributive effect of social security on a lifetime basis within the same generation, which has tended to be ignored in Japan.

The remainder of the paper is organized as follows: In section $\mathbf{2}$ we first overview the redistributive feature of a PAYGO system on a lifetime basis using a simple two-period life-cycle model. Based on that model, we analyze to what extent it can be affected by social security and tax reforms, such as removing the maximum contribution ("cap"), levying income tax on benefits, and using consumption tax to finance them. In section $\mathbf{3}$ we empirically illustrate to what extent the Kosei Nenkin program is actually progressive on a lifetime basis using reorganized data from the Survey. We also conduct some policy simulations to analyze how much policy reforms can potentially affect net lifetime income on average and its distribution. Section $\mathbf{4}$ provides a conclusion and points out issues that remain to be addressed.

\section{Theoretical Analysis}

\subsection{A simple model}

Let us consider a very simple two-period, life-cycle model, in which one works in period 1 and retires in period 2, to roughly capture the redistributive feature of social security ${ }^{1}$. Assume that in period 1 one gets wage income $(W)$ and pays a social security premium, which consists of a wage-proportional component (tW) and a flat component $(T)$. And, in period 2 he or she receives a social security benefit, which consists of a wage-proportional component $(b W)$ with a

\footnotetext{
1 In this paper, we focus on public pension programs, ignoring other social security programs such as medical, long-term care, and employment insurance.
} 
benefit multiplier $(b)$ and a flat component $(B)$. Hence, his or her net lifetime income $\left(W^{\star}\right)$ is generally expressed as

$$
W^{*}=(1-t) W-T+\frac{b W+B}{1+r},
$$

where $r$ is the interest rate. With no social security or under a funded system, net lifetime income is equal to gross income $(W)$. For simplicity, we assume that $W$ and $r$ are exogenously given and fixed, and we also neglect inheritances and private transfers.

Under a PAYGO system, the government has to balance the social security premiums (paid by individuals who are in period 1) and its benefits (paid to individuals who are in period 2) at each time: that is,

$$
(1+n)(t \bar{W}+T)=b \bar{W}+B,
$$

where $\bar{W}$ is average wage income and $n$ is rate of population growth. We assume a fixed rate of population growth. This assumption allows us to ignore issues related to intergenerational equity and concentrate on issues regarding (intergenerational) efficiency and intragenerational equity. We also assume that the level of a flat benefit $(B)$ is exogenously determined for a certain policy target, such as guaranteeing a "minimum standard of living" for the elderly. Then, under a benefit-defined scheme, the rate of the wage-proportional premium is implicitly derived as ${ }^{2}$

$$
t=\frac{1}{1+n}\left[b+\frac{B-(1+n) T}{\bar{W}}\right]
$$

It is widely recognized that a PAYGO system reduces net lifetime income if the population growth rate is lower than the interest rate, that is, if $n<r$. We can easily confirm this by substituting (2) into (1) to get

\footnotetext{
${ }^{2}$ The main results of the following discussions hold on the assumption of a contribution-defined scheme.
} 


$$
\bar{W}^{*}=(1-t) \bar{W}-T+\frac{b \bar{W}+B}{1+r}=\bar{W}-\frac{(r-n)(b \bar{W}+B)}{(1+r)(1+n)}<\bar{W} \text {, if } n<r
$$

for an individual of average income. This suggests that in order to reduce the negative impact of the system on lifetime income under an aging population the government should reduce social security benefits $(b \bar{W}+B)$; in other words, scale down the public pension program³.

It should be noted, but is often ignored, that a PAYGO system can make net lifetime income more equally distributed than the gross one within the same generation. To show this, we rewrite $W^{*}$ as

$$
W^{*}=\left(1-t+\frac{b}{1+r}\right) W-T+\frac{B}{1+r},
$$

which means that a PAYGO system can be interpreted as a life-cycle system of progressive income tax, as long as

$$
\frac{b}{1+r}<t<1+\frac{b}{1+r} \text { and } T<\frac{B}{1+r}
$$

Hence, a PAYGO system can reduce inequality in lifetime income. Indeed, the coefficient of variation $(\mathrm{CV})$ of net lifetime income, which is often used to gauge the relative inequality of income around its average, is calculated as

$$
C V\left(W^{*}\right)=\left[1-\frac{(1+n)(B-(1+r) T)}{(1+r)(1+n) \bar{W}-(r-n)(b \bar{W}+B)}\right] C V(W) \text {. }
$$

where the denominator of the second term in parentheses has to be positive to make net lifetime income positive. Simple calculations can show that if $T<B /(1+r)$, that is, if an individual gets a positive flat benefit net over lifetime, introduction of a PAYGO system reduces

3 Breyer (1989), Geanakoplos, Mitchell and Zeldes (1998), Sinn (2000), and many others pointed out, however, that scaling down a PAYGO system (or shifting to a funded system) does not allow for a Pareto-improvement, taking into account the need to compensate the existing pension liabilities. The same type of problem should occur in the transition process for any kind of reform, but is neglected in this paper. 
the relative inequality of lifetime income.

Then, what is the optimal PAYGO system in terms of both efficiency and intragenerational equity under an aging population, given the level of a flat benefit $(B)$ ? It is clear that a flat tax $(T)$ should be zero, because it does not affect average net income, but increases its inequality, as seen from (3) and (4). What of the benefit multiplier (b)? Assuming that $n<r$, a larger value of $b$ lowers the average net income (from (3)), but at the same time it reduces the CV (from (4)), because it requires a higher premium rate, which in turn adds to the progressivity of the system. Hence, the government will face a trade-off between efficiency and intragenerational equity: An efficiency- (intragenerational equity-) oriented government tends to choose a lower (higher) benefit multiplier. If the impact on the relative inequality of income is limited, however, the simplicity of the system?consisting of only a wage-proportional premium and a flat benefit?may look attractive.

If the government chooses this simple system, we can easily confirm that an individual with a lower income can get more net lifetime income than without a social security program, despite a reduction of average net lifetime income. Let us assume that $b=0, T=0$, and $t=B /[(1+n) t \bar{W}]$, making net lifetime income equal to

$$
W^{*}=\left[1-\frac{B}{(1+n) \bar{W}}\right] W+\frac{B}{1+r}=(1-t) W+\frac{(1+n) t \bar{W}}{1+r} .
$$

Hence, while this PAYGO system reduces average net lifetime income under an aging population with $n<r$ because

$$
\bar{W}^{*}=\bar{W}-\frac{(r-n) B}{(1+r)(1+n)}<\bar{W},
$$

it affects the net lifetime income of each individual differently in such a way that

$$
W^{*} \geq W \text { if } W \leq \frac{1+n}{1+r} \bar{W} ; \quad W^{*}<W \text { if } W>\frac{1+n}{1+r} \bar{W}
$$


This means individuals with lower incomes become better off at the expense of those with higher incomes under a PAYGO system ${ }^{4}$.

In summary, a PAYGO system has a favorable effect on income redistribution, in that it reduces the degree of inequality relative to average income, despite its adverse impact on average lifetime income under an aging population. This is because the impact of a reduced variance of net lifetime income more than offsets the impact of its lowered average. However, two things should be noted: first, this redistributive effect decreases with lower population growth, which tends to reduce average net lifetime income and raise its relative inequality; second, the redistributive effect increases with a higher level of benefit, which requires a higher premium rate.

\subsection{Annual vs. lifetime income redistribution}

The social security system, managed under a PAYGO scheme, entails income transfer from the young to the old at each time. In this sense, it makes annual income more equally distributed as long as the actual earnings of the old are lower than those of the young. Because everyone experiences being both young and old in his or her life, however, income redistribution on an annual basis should be interpreted with caution.

This section illustrates the relationship between the redistributive effect of a PAYGO system on annual and lifetime income, with annual income meaning "period" income in our simple two-period life-cycle model. To address this issue clearly, we take an extreme case in which the interest rate and the population growth rate are both equal to zero. We also assume that the social security system has a simple structure consisting of only a wage-proportional premium and a flat benefit. In this extreme case, the average gross annual income for society

\footnotetext{
4 This discussion also suggests that there are some individuals who become worse off under a PAYGO system, even if the population growth rate exceeds the interest rate.
} 
as a whole $\left(\bar{W}_{a}\right)$ is equal to $\bar{W} / 2$, because there are the same number of the young (who earn $\mathrm{W}$ ) and the old (who earn no income). So, the variance of gross annual income is given by

$$
V\left(W_{a}\right)=\frac{1}{2}\left(\bar{W}-\frac{\bar{W}}{2}\right)^{2}+\frac{1}{2}\left(0-\frac{\bar{W}}{2}\right)^{2}+\frac{V(W)}{2}=\frac{\bar{W}^{2}}{4}+\frac{V(W)}{2}
$$

adding the inter-age group and intra-age group variances. Hence, the squared coefficient of the variance (SCV) of gross annual income is given by

$$
\operatorname{SCV}\left(W_{a}\right)=V\left(W_{a}\right) / \bar{W}_{a}^{2}=1+2 \operatorname{SCV}(W),
$$

which is clearly larger than the SCV of gross lifetime income.

With the introduction of a PAYGO social security system, the net income of the young is $(1-t) W$ and that of the old is $B$, given the budget constraint per capita of $t \bar{W}=B$. Then, the average of net annual income $\left(\bar{W}_{a}^{*}\right)$ remains the same as $\bar{W} / 2$, and its variance is calculated in the same way as in the case of gross annual income:

$$
V\left(W_{a}^{*}\right)=\frac{(1-2 t)^{2} \bar{W}^{2}}{4}+\frac{(1-t)^{2} V(W)}{2}
$$

Then, the SCV of net annual income is

$$
\operatorname{SCV}\left(W_{a}^{*}\right)=V\left(W_{a}^{*}\right) / \bar{W}_{a}^{* 2}=(1-2 t)^{2}+2(1-t)^{2} \operatorname{SCV}(W),
$$

which is smaller than the SCV of gross annual income, because

$$
S C V\left(W_{a}^{*}\right)-S C V\left(W_{a}\right)=-2 t[2(1-t)+(2-t) S C V(W)]<0 .
$$

On the other hand, the SCV of net lifetime income is

$$
\operatorname{SCV}\left(W^{*}\right)=(1-t)^{2} \operatorname{SCV}(W),
$$

which is derived from (5) assuming $r=n$ and becomes clearly smaller than the SCV of gross lifetime income.

Now, let us compare the redistributive effects of the social security system on annual and lifetime income in terms of a change in the SCV: 


$$
\left|\frac{S C V\left(W_{a}^{*}\right)-S C V\left(W_{a}\right)}{S C V\left(W_{a}\right)}\right|-\left|\frac{S C V\left(W^{*}\right)-S C V(W)}{S C V(W)}\right|=\frac{t(2-3 t)}{1+2 S C V(W)}=\frac{B(2 \bar{W}-3 B)}{[1+2 S C V(W)] \bar{W}^{2}}
$$

Thus, the redistributive effect of the social security system, if evaluated as a reduction in the SCV of annual income, tends to be overestimated unless the benefit is extremely high. This result appears to basically hold with more realistic assumptions for economic and demographic variables, as well as with social security schemes, as already confirmed by several empirical studies quoted in section 1.

\section{3 Equal treatment of two occupational groups}

Next, let us discuss the plausibility of a pluralistic social security system, in which different schemes are applied to different occupational groups, before assessing the impact of policy reforms. The Japanese social security system basically consists of two schemes: one for employed workers (Kosei Nenkin and Kyosai Kumiai) and the other for self-employed workers (Kokumin Nenkin). The former scheme has a wage-proportional premium and a "double-decker" benefit, which consists of a wage-proportional component and a flat component. For the latter scheme, both the premium and the benefit are flat. The budget accounts of Kosei Nenkin, Kyosai Kumiai, and Kokumin Nenkin are connected with each other, and the level of the flat component is set to be the same for all schemes and is called Kiso Nenkin (Basic Pension Benefit). In addition, one third of the flat component is covered by the government subsidy, which is financed by income tax and other taxes ${ }^{5}$.

Consider a two-group model, which roughly mirrors this Japanese social security system. Each individual belongs to either group 1, which pays a wage-proportional premium and receives a "double-decker" benefit, or group 2, which pays a flat premium and receives a flat

\footnotetext{
5 The 2000 Pension Reform called for a rise in this subsidy ratio to $1 / 2$ as of 2004 .
} 
benefit. Under this model, net lifetime income for each group is respectively given by

$$
\begin{aligned}
& \text { Group 1: } W_{1}^{*}=(1-t-\tau) W_{1}+\frac{b W_{1}+B}{1+r}, \\
& \text { Group 2: } W_{2}^{*}=(1-\tau) W_{2}-T+\frac{B}{1+r},
\end{aligned}
$$

where $\tau$ is the rate of additional wage-proportional income tax that finances the government subsidy for the common flat benefit. We assume that this income tax is levied only on young workers. The budget constraint of the government is expressed as

$$
(1+n)\left[\tau\left(\phi \bar{W}_{1}+(1-\phi) \bar{W}_{2}\right)+\phi t \bar{W}_{1}+(1-\phi) T\right]=\phi b \bar{W}_{1}+B
$$

with $\phi$ denoting the population share of group 1 members. Here, we assume that the budget constraints of two social security programs are integrated for society as a whole, reflecting the current scheme in Japan. The population size of each group is set to grow at the same $n$ and no movement of members between groups is allowed. Assuming that $\theta{ }^{*} 100 \%$ of $B$ is covered by the government subsidy, we get the budget constraint for the flat benefit of

$$
(1+n) \tau\left[\phi \bar{W}_{1}+(1-\phi) \bar{W}_{2}\right]=\theta B
$$

which compresses (8) to

$$
(1+n)\left[\phi t \bar{W}_{1}+(1-\phi) T\right]=\phi b \overline{W_{1}}+(1-\theta) B
$$

Because the government has no reason to treat the two groups unequally, it has to make the formulae (7a) and (7b) effectively the same for any level of wage earnings. Because (7b) is rewritten as

$$
W_{1}^{*}=(1-\tau) W_{1}+\left(\frac{b}{1+r}-t\right) W_{1}+\frac{B}{1+r}
$$

one plausible way to do this is to arrange the premium and the benefit so that

$$
t=\frac{b}{1+r}, T=0
$$


If the government wants to maintain a wage-proportional premium for group 2 to finance the benefit for institutional reasons, this is the only arrangement that is available and desirable. Then, the budget constraint ( 8$)^{\prime}$ is

$$
\phi(n-r) b \bar{W}_{1}=(1-\theta)(1+r) B .
$$

Because $n<r$ with an aging population and assuming $B>0$, we obtain:

$$
b=0, \theta=1,^{6}
$$

which lead to $t=0$. Therefore, both groups have to have only a common and flat benefit $(B)$, and pay a wage-proportional premium with the common tax rate $(\tau)$, which is equivalent to the simple PAYGO system discussed in 2.1.

\subsection{Redistributive impact of the "cap" system}

The social security systems for employed workers in Japan?the Kosei Nenkin and Kyosai Kumiai?have an upper ceiling of wage earnings for calculating wage-proportional premiums and benefits, as observed in many other countries. This section analyzes the redistributive feature of this "cap" system. Denote $A$ as the cap and divide the whole population into two income classes: a higher income class and a lower income class, with the income level of $A$ as a threshold, then the net lifetime income of each class is given by

$$
\begin{aligned}
& \text { Higher-income class: } W^{*}=W-t^{\prime} A-T+\frac{B+b A}{1+r} \text {, if } W>A, \\
& \text { Lower-income class: } W^{*}=\left(1-t^{\prime}+\frac{b}{1+r}\right) W-T+\frac{B}{1+r} \text {, if } W \leq A,
\end{aligned}
$$

where $t$ is a wage-proportional premium rate under the cap system. The budget constraint for society as a whole is expressed as

\footnotetext{
${ }^{6}$ This means that the Japanese two-group model with a partial government subsidy for the common flat benefit can be justified only under modest population growth with $n>r$.
} 


$$
(1+n)\left[\left(\varphi A+(1-\varphi) \bar{W}_{-}\right) t^{\prime}+T\right]=\left[\varphi A+(1-\varphi) \bar{W}_{-}\right] b+B,
$$

where $\varphi$ is the population share of the higher-income class and assumed to be constant, and $\bar{W}_{+}\left(\bar{W}_{-}\right)$is the average income of the higher income (lower income) group. With $B, T$, and $b$ given exogenously, the premium rate is implicitly solved as

$$
t^{\prime}=\frac{1}{1+n}\left[b+\frac{B-(1+n) T}{\varphi A+(1-\varphi) \bar{W}_{-}}\right]
$$

which can be shown to be higher than the premium rate $(t)$ under a no-cap system that is given by (2), so long as $B>(1+n) T$.

How should this cap system be assessed in terms of efficiency and equity? It raises the average net lifetime income, because from (9a) and (9b) we get

$$
\varphi \bar{W}_{+}^{*}+(1-\varphi) \bar{W}_{-}^{*}=\bar{W}^{*}+\frac{\varphi\left(\bar{W}_{+}^{*}-A\right)(r-n) b}{(1+n)(1+r)}>\bar{W}^{*}
$$

assuming $n<r$. However, the impact works asymmetrically on two income classes: it is favorable for a higher income class but not for a lower income class. It can be confirmed as follows. The average net lifetime income for the higher income class $\left(\bar{W}_{+}^{*}\right)$ is higher than that under a no-cap system, because

$$
\bar{W}_{+}^{*}-\left[\left(1-t+\frac{b}{1+r}\right) \bar{W}_{+}-T+\frac{B}{1+r}\right]=\frac{\bar{W}_{+}-A}{1+n}\left[\frac{(r-n) b}{1+r}+\frac{(1-\varphi) \bar{W}_{-}(B-(1+n) T)}{\bar{W}\left(A \varphi+(1-\varphi) \bar{W}_{-}\right)}\right]>0,
$$

assuming $B>(1+n) T$ and $n<r$. For a lower income class, on the contrary, the average net lifetime income becomes lower, because

$$
\bar{W}_{-}^{*}-\left[\left(1-t+\frac{b}{1+r}\right) \bar{W}_{-}-T+\frac{B}{1+r}\right]=\left(t-t^{\prime}\right) \bar{W}_{-}<0 .
$$

Hence, the cap system is expected to widen the inter-group gap for net lifetime income compared to that under a no-cap system. This impact itself adds to the relative inequality of income distribution. Meanwhile, the intra-group variance of net lifetime changes in opposite 
directions for the two income classes: (9a) and (9b) suggest that for the higher income class the variance remains the same as the gross one, and is thus larger than net income without a cap, while the variance for the lower-income class is smaller than that without a cap due to a higher premium rate. Hence, the direction of a change in the redistribution effects is indeterminate ${ }^{7}$.

\subsection{Taxation}

The Japanese system of income taxation is often criticized for being too generous to the elderly, who can enjoy several income exemptions for taxation. Actually, most pensioners do not need to pay any income tax on benefits. With a deterioration of social security finances in prospect, some argue for raising income tax on benefits or increasing consumption tax to hold down PAYGO burdens, which are currently levied exclusively on young people. Such tax policies are likely to reduce the adverse income transfer between generations and raise average net lifetime income with an aging population. Yet, it is uncertain whether or not it can reduce the inequality of lifetime income within the same generation.

Let us consider the system in which the government finances a flat social security benefit by a wage-proportional tax (with a tax rate $t_{\mathrm{i}}$ ), which is commonly levied on both young and old people, and compare this case to the simple PAYGO system described in 2.1. The budget constraint per capita of the social security system will be expressed as

$$
t_{i}[(1+n) \bar{W}+B]=B,
$$

which is given from (1) setting $T=b=0$. Then, net lifetime income $\left(W_{i}^{*}\right)$ is expressed as

$$
W_{i}^{*}=\left(1-t_{i}\right)\left(W+\frac{B}{1+r}\right)=\left[1-\frac{B}{(1+n) \bar{W}+B}\right]\left(W+\frac{B}{1+r}\right)
$$

\footnotetext{
7 Shimono and Tachibanaki (1985)'s numerical analysis pointed out that removing the cap has a limited impact on income redistribution in Japan. Meanwhile, Coronado et al. (2000) showed that this type of reform makes the system less progressive in the United States.
} 
The effects of this taxation are mixed. On the one hand, with the same level of benefit $(B)$, average net income is higher than in the case with no tax on benefit. To show this, we compare (11) to (6):

$$
\bar{W}_{i}^{*}=\left[1-\frac{B}{(1+n) \bar{W}+B}\right]\left(\bar{W}+\frac{B}{1+r}\right)=\bar{W}^{*}+\frac{(r-n) B^{2}}{(1+r)(1+n)[(1+n) \bar{W}+B]}>\bar{W}^{*}
$$

assuming $n<r$. This result makes sense intuitively, because taxing the benefit spreads social security costs more widely among different generations, and mitigates intergenerational transfers with an aging population. On the other hand, the variance of net lifetime income becomes larger, because $t_{\mathrm{i}}$ is clearly lower than $t$ and thus reduces the progressivity of the system. Putting these factors together, we get the coefficient of variance of net lifetime income, which is equal to

$$
C V\left(W_{i}^{*}\right)=\frac{(1+r) \bar{W}}{(1+r) \bar{W}+B} C V(W)
$$

Besides, we can show that

$$
\frac{C V\left(W_{i}^{*}\right)}{C V\left(W^{*}\right)}=\frac{(1+r)(1+n) \bar{W}^{2}-(r-n) B \bar{W}}{(1+r)(1+n) \bar{W}^{2}-(r-n) B \bar{W}-B^{2}}>1
$$

which indicates that taxing the benefit reduces the redistributive effect of a PAYGO system within the same generation. Hence, income taxation on the benefit is desirable in terms of efficiency, but is undesirable in terms of intragenerational equity.

How will these results change when applying consumption tax, which is levied on consumption expenditures of both the young and old, instead of income tax to finance social security benefits? To answer this question, we take a simple case in which an individual consumes all of his or her net lifetime income leaving no bequest, and smoothes consumption over lifetime to maximize his or her utility. Denote consumption in periods 1 and 2 as $C_{1}$ and $C_{2}$, respectively, with a consumption tax rate of $t_{c}$, and assume that the lifetime utility function of 
an individual is expressed as

$$
U\left(C_{1}, C_{2}\right)=\ln C_{1}+\frac{1}{1+r} \ln C_{2},
$$

where the discount rate of utility in period 2 is assumed to be equal to the interest rate.

Then, on average for society as a whole consumption in each period is given as:

$$
\bar{C}_{1}=\bar{C}_{2}=\frac{1+r}{\left(1+t_{c}\right)(2+r)}\left(\bar{W}+\frac{B}{1+r}\right)
$$

and considering that the budget constraint of the social security system is given by

$$
t_{c}\left[(1+n) \bar{C}_{1}+\bar{C}_{2}\right]=B,
$$

the consumption tax rate is implicitly solved as

$$
\frac{t_{c}}{1+t_{c}}=\frac{B(2+r) /(2+n)}{[(1+r) \bar{W}+B]}
$$

Hence, net lifetime income $\left(W_{c}^{*}\right)$ is given by

$$
W_{c}^{*}=\frac{1}{1+t_{c}}\left(W+\frac{B}{1+r}\right)=\left[1-\frac{B(2+r) /(2+n)}{(1+r) \bar{W}+B}\right]\left(W+\frac{B}{1+r}\right)
$$

and its average is calculated as

$$
\bar{W}_{c}^{*}=\left[1-\frac{B(2+r) /(2+n)}{(1+r) \bar{W}+B}\right]\left(\bar{W}+\frac{B}{1+r}\right)=\bar{W}^{*}+\frac{(r-n) B}{(1+r)(1+n)(2+n)}>\bar{W}^{*} .
$$

Comparing this with (12), we get

$$
\bar{W}_{c}^{*}=\bar{W}_{i}^{*}+\frac{(r-n) B(\bar{W}-B)}{(1+r)(2+n)[(1+n) \bar{W}+B]}>{\overline{W_{i}}}^{*}
$$

assuming $n<r$ and $B<\bar{W}$. Hence, consumption tax becomes more efficient than wage-proportional income tax with an aging population, as long as the social security benefit is lower than wage earnings. This is because in period 2 an individual consumes more than the benefit, and thus pays more (consumption) tax than in the case of income tax, which is levied 
not on the benefit but on consumption expenditures. Thus, consumption tax can suppress income transfer from the young to the old under an aging population more effectively than income tax.

Meanwhile, as seen in (16), net lifetime income is proportional to the sum of wage and present discounted value of the benefit, as in the case of income taxation on the benefit (see (11)). Thus, these two types of taxation have the same CV of net lifetime income, which is expressed in (13). Therefore, under an aging population, consumption tax is superior to income tax for financing a social security benefit, because it leads to a smaller reduction in average net lifetime income without increasing the relative inequality of lifetime income.

This assessment of consumption tax, however, would be affected by introducing "price indexation," which automatically raises the level of benefit (as well as after-tax consumer prices) by as much as the consumption tax rate. Starting with no consumption tax, the benefit is inflated to $\left(1+t_{\mathrm{cc}}\right) B$, where $t_{\mathrm{cc}}$ is a modified consumption tax rate at an equilibrium. Thus, the budget constraint of the social security system is given by

$$
t_{c c}\left[(1+n) \overline{C_{1}}+\overline{C_{2}}\right]=\left(1+t_{c c}\right) B,
$$

and the consumption tax rate is implicitly solved as the value that satisfies

$$
\frac{t_{c c}}{1+t_{c c}}=\frac{\left(1+t_{c c}\right) B(2+r) /(2+n)}{\left\lfloor(1+r) \bar{W}+\left(1+t_{c c}\right) B\right]}
$$

assuming the individual's utility function (14). This modified consumption tax rate can easily be shown to be higher than the consumption tax rate with no price indexation $\left(t_{c}\right)$, because the government has to finance the benefit inflated by price indexation. Net lifetime income $\left(W_{c c}^{*}\right)$ and its average are given respectively by

$$
W_{c c}^{*}=\frac{1}{1+t_{c c}}\left[W+\frac{\left(1+t_{c c}\right) B}{1+r}\right]=\left[1-\frac{\left(1+t_{c c}\right) B(2+r) /(2+n)}{(1+r) \bar{W}+\left(1+t_{c c}\right) B}\right]\left[W+\frac{\left(1+t_{c c}\right) B}{1+r}\right]
$$




$$
\bar{W}_{c c}^{*}=\bar{W}^{*}+\frac{(r-n) B\left[1-(1+n) t_{c c}\right]}{(1+r)(2+n)},
$$

the latter of which leads to: $\bar{W}_{c c}^{*}>\bar{W}^{*}$ provided the consumption tax rate is lower than $1 /(1+n)$, and also to: $\bar{W}_{c c}^{*}<\bar{W}_{c}^{*}$ from (16). It is, however, indeterminate whether or not $\bar{W}_{c c}^{*}>\bar{W}_{i}^{*}$, because a higher benefit requires a higher consumption tax, which in turn raises its rate via price indexation of the benefit. ${ }^{8} \quad$ Meanwhile, the $\mathrm{CV}$ of net lifetime income is given by

$$
C V\left(W_{c c}^{*}\right)=\frac{(1+r) \bar{W}}{(1+r) \bar{W}+\left(1+t_{c c}\right) B} C V(W),
$$

which is lower than that in the case of income taxation or consumption tax without price indexation (see (13)). However, we can show that consumption tax with price indexation cannot reduce the $\mathrm{CV}$ of net lifetime income from the level with no taxation on the benefit, as far as $n<r$. Consumption tax, if price-indexed, makes both the benefit and the tax rate higher, which adds to the progressivity of consumption tax, but this effect is more than offset by a reduction of net lifetime income with an aging population.

In sum, the analysis in this section concludes:

(i) income tax on the benefit makes average net lifetime income higher than in the case of no taxation on the benefit, while it widens its relative inequality within the same generation;

(ii) consumption tax with no price indexation is preferable to income tax, in that the former makes average net lifetime income higher than the latter, while these two tax policies lead to the same relative inequality of income distribution;

(iii) consumption tax with price indexation makes average net lifetime income lower than

\footnotetext{
${ }^{8}$ Simple calculations show that a higher benefit makes average net lifetime income lower provided $r>n$, and that it is necessary for the tax and the benefit to satisfy the condition: $B<\left[1-(1+n) t_{c c}\right] \bar{W} /\left(1+t_{c c}\right)$ in order to make $\bar{W}_{c c}^{*}>\bar{W}_{i}^{*}$. This condition can be simplified to: $B<W / 3$ if $n=r=0$, implying that consumption tax with price indexation is more efficient than income tax if the level of social security benefit is relatively low. This condition becomes stricter with an aging population.
} 
consumption tax with no price indexation and possibly of income tax (but still higher than in the case of no taxation on the benefit), while it makes net lifetime income more equally distributed than those two types of taxation.

Discussions in this section are for a simple social security system that has only a flat benefit and a wage-proportional premium as a baseline, but the key messages are likely to hold with a more realistic system.

\section{Empirical Analysis}

\subsection{Measurement of redistributive effects and progressivity}

It is almost impossible to directly measure the impact of social security programs on lifetime income in Japan, because no panel data are available that provide a profile of wage income, social security contributions, and benefits. Our analysis thus depends heavily on cross-section data of the 1996 Survey on the Redistribution of Income, which was conducted and published by the Ministry of Health and Welfare (which is now the Ministry of Health, Labor, and Welfare). The Survey reports an individual's wage, social security contributions and benefits, and income and other taxes, with his/her family, spousal, and occupational characteristics in the survey year, but no longitudinal information is available.

There are several ways to evaluate the overall redistributive effects and progressivity of the system. In this paper, we use three measures. First, we calculate a change in the SCV, for which a larger reduction means more redistribution of income. The SCV is useful in that its change can be easily decomposed as:

$$
\begin{aligned}
\frac{S C V\left(W^{*}\right)-S C V(W)}{S C V(W)}= & \frac{1}{V(W)} \sum_{i} \omega_{i}\left[\left(\bar{W}_{i}^{*}-\bar{W}^{*}\right)^{2}-\left(\overline{W_{i}}-\bar{W}\right)^{2}\right] \\
& +\frac{1}{V(W)} \sum_{i} \omega_{i}\left[V\left(W_{i}^{*}\right)-V\left(\bar{W}_{i}\right)\right]+\frac{\bar{W}^{2}-\bar{W}^{* 2}}{\bar{W}^{* 2}} \frac{V\left(W^{*}\right)}{V(W)},
\end{aligned}
$$


where $\omega_{i}$ is a share of each group of a society. The first and second terms of the right hand side indicate changes in the intra-group and inter-group variances, respectively, of income due to redistribution by he social security system. The third term shows the degree of "incompleteness" of income redistribution, which Oshio (2002) discussed in more detail. The social security system is usually incomplete in terms of income redistribution, in that its benefits are covered not only by employees' own contributions but also employers' contributions and government subsidy (which is eventually to be financed by tax), making the average net income higher than gross income, thus lowering the $\mathrm{SCV}^{9}$. We have to take into account this incompleteness in order to precisely assess redistribution policies.

Second, we compare the Gini indices before and after social security taxes and benefits. The progressivity can be gauged by the "effective progression" (EP) measure of Musgrave and Thin (1948), also used by Coronado et al. (2000) and others:

$$
E P=\frac{1-\operatorname{Gini}_{A T}}{1-G i n i_{B T}}
$$

where Gini $_{\mathrm{AT}}$ and $\mathrm{Gini}_{\mathrm{BT}}$ are before-tax-and-benefit and after-tax-and-benefit Gini indices. A value of one indicates that $\operatorname{Gini}_{A T}$ and Gini $_{B T}$ are the same, and that social security has no impact on income distribution. A value greater than one indicates a progressive system, and a value less than one indicates regressivity of the system.

Third, we compare the magnitude of the net social security tax by income class. The net social security tax rate is defined as the magnitude of the difference between the present discounted value of premiums or taxes paid and benefits received, relative to gross lifetime income. If higher income individuals face a higher net social security tax rate, we can

\footnotetext{
9 This incompleteness could be caused by an insufficient sample size rather than institutional factors. Our sample size, however, seems to be large enough to neglect this possibility and the data are randomly selected.
} 
conclude that the system is progressive. We focus on this tax rate when assessing the redistributive impact of policy reforms in 3.4 .

First, let us provide a rough picture of income redistribution through the social security system as a whole?including all members of Kosei Nenkin, Kyosai Kumiai, and Kokumin Nenkin?on an annual basis. The top part of Table 1 summarizes income redistribution through the social security programs as a whole, based on all individuals classified into two age groups: the young (aged 20-59) and the old (aged 60+). The sample size is 18,253 , with 12,888 young and 5,365 old individuals of all kinds of occupational status, including non-working housewives. Income data are on an individual basis, with net income calculated as gross income plus social security benefits minus premiums. Gross income in the table is the one reported by each individual in the Survey without any adjustment (see in 3.2).

As can be seen from this table, a significant part of a $21.3 \%$ reduction in the SCV is attributable to the "incompleteness" of the programs, which reduces the SCV by $13.3 \%$ points. This is consistent with a gap between averages of net and gross income caused by two factors: first, employers pay half of required premiums (gross income reported in the Survey excludes employers' contributions), and second, the government subsidizes one third of the flat Basic Benefit given to the elderly. Aside from the effects of this incompleteness, the social security programs reduce the inter-age group variance of annual income by $4.6 \%$ points through income transfers from the young to the old, and they reduce the intra-age group variance by 3.3\% points, mainly through income redistribution among the young.

Then we focus on employed workers and pensioners, both of whom seem to be Kosei Nenkin or Kyosai Kumiai members. We select those $(4,876)$ who are aged $20-59$ and pay Kosei/Kyosai premiums and those $(2,154)$ who are aged $60+$ and receive Kosei/Kyosaibenefits. The latter individuals are considered to have been employed workers, part-time or full-time, and paid contributions to Kosei/Kyosai programs before age 60 . The bottom part of Table 1 
summarizes the results, which are different from those for all individuals. The redistributive impact of Kosei/Kyosai programs, which lowers the SCV by $36.5 \%$, is somewhat stronger than that observed for all individuals. This is largely due to substantial income transfers from the young to the old, in line with a remarkable reduction of the inter-age variance of net income. On the other hand, the SCV for the young remains little changed, because premiums are basically wage-proportional. A reduction of the SCV for the old is mostly due to a rise in net income, which is boosted by the benefit. The level of the incompleteness effect is almost the same as that observed for all individuals.

The numbers in the last rows in the both parts of Table 1 report the effective progression of the social security programs: 1.206 for the total sample and 1.227 for Kosei/Kyosai members. These values indicate that the current social security system is progressive in terms of annual income, which is in line with the above-mentioned results based on a change of the SCV.

\subsection{Modifying annual income and setting up lifetime income}

To quantify the redistributive effects of social security more precisely, we modify and reorganize the data from the Survey. First, we modify "gross income" so that it includes employers' contributions to social security, because gross income reported in the Survey excludes them. Consequently, gross income hereafter means total compensation paid by an employer, which is equivalent to "employment compensation" on a national accounts basis. We need to make this modification to get a comprehensive picture of income redistribution. We also assume that this redefined gross income is fixed regardless of policy changes; for example, even if a new system allows employers to pay no social security contributions, they are assumed to make the same contributions as they have to pay under the current system on wages.

When calculating this redefined gross income, we take into account the relationships among redefined gross income $\left(W_{\mathrm{a}}\right)$, reported gross income $\left(W_{\mathrm{a}}^{\mathrm{R}}\right)$, and "standardized" income 
[hyojun hoshu] (on which the social security premiums are levied and which is capped with $A$ as the maximum for calculating premiums) $\left(W_{\mathrm{a}}^{\mathrm{S}}\right)$ :

$$
W_{a}^{R}=W_{a}-\frac{t_{0}}{2} W_{a}^{S}, W_{a}^{S}=\min \left[A,(1-\lambda) W_{a}^{R}\right]
$$

where $t_{0}$ is the premium rate and $\lambda$ denotes the share of bonus payments in reported gross income. Assuming for simplicity that $\lambda$ is equal for all employees and neglecting the employers' contributions to other social security programs, we estimate gross income from the reported one by

$$
\begin{aligned}
& W_{a}=\left[1+\frac{(1-\lambda) t_{0}}{2}\right] W_{a}^{R} \text { if } W_{a}^{R} \leq \frac{A}{1-\lambda}, \\
& W_{a}=W_{a}^{R}+\frac{t_{0} A}{2} \text { otherwise. }
\end{aligned}
$$

Reflecting the current Kosei Nenkin program, we set $t_{0}=0.165$ and $A=7,080,000$ yen $(=590,000$ yen/month $\times 12$ months), both of which are statutory parameters in the survey year of 1996 , and also that $\lambda=1 / 4$ is close to the average among Japanese employees.

Second, and more importantly, we have to set up lifetime income. Because no panel data are available in Japan, we reorganize the micro-data of the Survey to roughly estimate lifetime income, and then we evaluate the potential redistributive effects of the social security system, focusing on the Kosei Nenkin program.

We reorganize the micro-data in the following ways. First, we choose only male employees in the private sector aged 59 or under from the Survey. Second, we classify these individuals into eight age groups at intervals of five years, from 20-24 years old to 55-59 years old. Third, we divide each age group into 20 income classes, to get $160(=8 \times 20)$ "cells" in total. Fourth, we calculate average income and Kosei Nenkin premiums for each cell through age 50-59. Then, we assume that each individual stays at one of 20 income classes at each 
of the life stages and earns income and pays premiums, which are estimated to be earned on average at each cell based on the micro-data ${ }^{10}$.

Naturally, each individual may move from one income class to another at each life stage. So, we tentatively define "the degree of immobility" of income classes as $\alpha(0 \leq \alpha \leq 1)$; if the individual belongs to income class $j$ at any life stage, the individual will remain in the class $j$ at the next life stage with a probability of $(1+2 \alpha) / 3 \times 100 \%$, and move to the neighboring class $j-1$ or class $j+1$ with a probability of $(1-\alpha) / 3 \times 100 \%$, respectively (as illustrated in Figure 1 ). The individual is assumed to move to no other classes for simplicity. And if the individual belongs to either the 1st (the poorest) class or the 20th (the richest) class at any life stage, we assume that the probability of remaining in that class is $(2+\alpha) / 3 \times 100 \%$ at the next stage, and that the probability of moving to either the 2 nd class or the 19 th class is $(1-\alpha) / 3 \times 100 \%$. Lifetime income is calculated as the expected value of the present discounted income obtained by this simulation.

If $\alpha=1$, that is, if we assume no mobility between income classes, each individual will continue to belong to the income class to which he belongs when he is in the $20-24$ age bracket until they reach the 55-59 age bracket. Therefore, the income distribution observed by the cross-section analysis of the age groups from the 20-24 to 55-59 age brackets will be presented in exactly the same form as it is. However, it is easy to prove that whatever value $\alpha$ may have?that is, whatever lifetime income distribution may look like?the annual income distribution shown in the Survey will be reproduced as it is. Put another way, we create synthetic streams of individuals' lifetime income that would always reproduce the annual income distribution shown in the Survey. We ignore here a variety of factors affecting income

\footnotetext{
${ }^{10}$ In the United States, there have been several pieces of research using arbitrary levels of income for different groups to analyze intragenerational redistribution of social security. See Boskin, Kotlikoff, and Puffert (1987) for example.
} 
redistribution, such as cohort effects and technical development. However, we believe that this is one of the most easily tractable methodologies for grasping a rough picture of lifetime income distribution, which is consistent with the cross-section actual data, especially with limited longitudinal information.

For calculations of social security benefits, we assume that Kosei Nenkin members pay premiums for forty years from 20 to 59 years of age, retire completely at age 60 , and then depend entirely on benefits (without any other income) until they die at age 80 . The benefit multiplier (b) for the wage-proportional component of the benefit is 0.3 (for those who have paid premiums for forty years), and the amount of the flat Basic Benefit $(B)$ is $1,560,000$ yen (=65,000 yen/month $\times 12$ months $\times 2$ persons) a year, which is paid to them and their wives. ${ }^{11}$ For simplicity, we assume no price and wage inflation, which means that the wage proportional component of the benefit is proportional to?that is, $30 \%$ of?the average nominal annual wage earnings. The data for pension benefits and retirement lump-sum payments for the elderly can be obtained from the Survey, but are disregarded because it is impossible to trace the relations with their income when they were active workers. Income other than employment income, such as interest and dividend income is also ignored for the same reason.

\subsection{Redistributive effect of the Kosei Nenkin program}

This section provides a simple and rough assessment of the redistributive effect of the current Kosei Nenkin program, based on our society, which is composed of 240 individuals in total (12 age groups (20-24 to $75-79$ years) $\times 20$ income classes). Table 2 summarizes it. We assume that the population shrinks $0.5 \%$ at an annual rate, close to the trend in recent decades, meaning that older age groups occupy higher shares of population.

\footnotetext{
${ }^{11}$ Our samples are all males and we assume that they all have non-working dependent wives, who get the flat Basic Benefits without any contributions.
} 
First, we measure progressivity on an annual basis, using the $16.5 \%$ premium rate and leave the "incompleteness" of the system as it is ${ }^{12}$. As reported in the "Incomplete System" part of Table 2, the SCV of gross annual income of these groups is 0.986 , which is somewhat higher than the actual value of 0.825 shown in Table 1 (2). This difference is mainly due to the assumption in Table 2 that individuals have no earnings except social security benefits after retirement, leading to higher differentials of annual income between young and old. The Kosei Nenkin program reduces the SCV by $65.4 \%$ but $11 \%$ points of it (not shown in the table) must be fulfilled by resources other than Kosei Nenkin premiums, in line with the result that average net annual income is $14.8 \%$ higher than gross income. Besides, the estimated effective progression is 1.4898 , confirming the system's substantial redistribution on an annual basis.

Now we focus on the redistributive effects on a lifetime basis. We compare the results with three different interest rates $(i=1 \%, 2 \%$, and $3 \%$ at an annual rate) and three degrees of immobility of income classes $(\alpha=0,0.5$, and 1$)$. As can be clearly seen in Table 2 , the redistributive effects on a lifetime basis are much more limited than on an annual basis, and depend on the interest rate as well as the degree of immobility of income classes. The reduction of the SCV is in the $8-16.1 \%$ range and the effective progression is in the $1.01-1.02$ range, both of which are much smaller than observed on an annual basis ${ }^{13}$. A higher interest rate reduces the progressivity of the Kosei Nenkin program, because it lowers net lifetime income due to a PAYGO structure and increases its relative inequality. Indeed, if the interest rate is as high as $3 \%$, net lifetime income falls short of gross income, despite the government

\footnotetext{
12 However, it should be noted that employers' contributions are reflected in the calculations, unlike in Table 1.

${ }_{13}$ Using Dutch micro data, Nelissen (1998) reported similar results to this paper, including the fact that the lifetime income-based redistribution effect of social security tends to be less than annual income-based effects, and that if the discount rate rises, redistribution effects decrease. Nelissen (2000) also compared the redistributive impacts of several Dutch social security programs on a lifetime basis.
} 
subsidy for the benefit. On the other hand, lower mobility of income classes?that is, a higher value of $\alpha$ ?reduces the progressivity of the system, but not substantially because it raises the inequality of both gross and net income.

How will these results change if we adjust the premium rate to make the system "complete," that is, to make total premium revenues and total benefit payments balanced every year? By making the system complete, we provide a steady-state picture of intragenerational redistribution in the "Complete System" part of Table 2. The premium rate is endogenously solved as $37.5 \%$, which is much higher than the current $16.5 \%$, and strongly raises concerns about the sustainability of the current system, which relies heavily on future generations' burdens and/or financial sources other than social security premiums ${ }^{14}$. This high premium rate adds to redistributive effects and progressivity on an annual basis, but it reduces them substantially on a lifetime income basis, mainly due to a sharp drop in average net income under an aging society. If the interest rate is as high as $3 \%$ and there is limited mobility of income classes, it is quite difficult to justify the current system, as it reduces lifetime income by $17 \%$ but makes little improvement in the equality of income distribution.

\subsection{Policy simulations}

This section makes some policy simulations and compares the impacts of five pension and tax reforms on lifetime income and its distribution, taking as a benchmark the current system, which is made "complete" by the endogenously solved premium rate (37.5\%), and assuming

\footnotetext{
${ }^{14}$ This endogenously determined premium rate in our model is not affected by the assumptions on the interest rate or the degree of income class immobility, because 1) it is determined to balance premiums and benefits on an annual basis and 2) the actual distribution of annual income is reproduced regardless of the immobility of income class. On the other hand, $37.5 \%$ seems to be prohibitively high, but the Ministry of Health, Labor and Welfare stated in its report (May, 2002) that the premium rate has to be eventually raised to $29-35 \%$ to maintain the current level of pension benefits. In addition, these figures in MHLW's estimates do not include taxes to finance the government subsidy for the Basic Pension benefits.
} 
that the interest rate is $2 \%$ and the degree of immobility is 0.5 . We conducted several simulations assuming different values for the degree of immobility, obtaining only minor differences in results.

First, we remove the cap on earnings and take into account each individual's full monthly income (excluding bonus payments) (reform I). Discussions in 2.4 suggest that this reform will reduce average net income, whereas its redistributive effect is indeterminate because the intra-group variance of net lifetime changes in opposite directions for the two income classes. Table 3 shows that the premium rate falls to $27.2 \%$, reflecting a broader tax base, and that the redistributive effect becomes much stronger with a limited change of average net income.

Figure 2, which compares each reform's impact on lifetime income by income class, helps to explain this result. In this figure we compare the magnitude of the net social security tax relative to gross lifetime income. Under the current system, upper middle income classes face a higher net tax rate than any other class, largely because the cap system reduces the decrease in income for higher income classes. Removal of the cap called for by reform I makes the tax curve slope monotonically upward, enhancing the overall progressivity of the system. In addition, tax reductions in lower income classes and tax increases in higher income classes largely offset each other, leading to a limited increase in the average net lifetime income. Once the cap is removed, shifting the tax base from monthly income to annual income (which includes bonus payments) ${ }^{15}$ does not matter in our model, provided we assume that the share of bonus payments is the same (1/4) for all individuals, and that the government reduces the benefit multiplier (to $22.5 \%[=30 \% \times(1-1 / 4)]$ ) to keep the level of

\footnotetext{
${ }^{15}$ This reform was actually implemented as of April 2003. However, it should be noted that its impact will not be recognized soon, because it will take several years for the base for calculating wage-proportional benefits to completely shift to annual income from the current monthly (standardized) income. Thus, we should interpret the simulation results reported here as a long-run, potential impact of the reform. In our simulations, the benefit multiplier is endogenously solved to be $24.81 \%$ in reform $\mathrm{I}$.
} 
benefits unchanged.

For reform II, we remove the wage-proportional component from the benefit on top of reform I. Individuals now pay a wage-proportional premium when young (with no cap) and receive a flat benefit when old. As implied in the discussions in 2.1, this reform is expected to raise net lifetime ncome, but widen its relative inequality, making the government face a trade-off between efficiency and intragenerational equity. According to our simulation, the required premium rate falls remarkably to $14.3 \%$, which suppresses the reduction of average lifetime income to $7.2 \%$. On the other hand, the reduction of the progressivity from reform I becomes quite limited, probably because a remarkable rise in average income appears to largely offset the effect of an increase in its variance of income. This situation is also consistent with a substantial downward shift of the tax curve in Figure 2, which shows an increase in net lifetime income across income classes, and contributes to a reduction of its relative inequality.

Accordingly, we can state that downsizing the social security system to a simple one whose benefit has only a flat component succeeds in raising net lifetime income on average, without substantially raising its relative inequality compared to the current system. On an annual income basis, by contrast, it leads to a substantial reduction of progressivity, because the young pay less and the old receive less.

Reform III uses income tax, which is commonly applied to wages earned by the young and benefits received by the old, instead of premiums, to finance the flat benefits. The tax base includes bonus payments. The tax rate is now endogenously solved as $12.5 \%$, which is somewhat lower than the premium rate $14.3 \%$ in reform II, because not only the working young but also the retired old finance benefits. In line with expectations based on the discussions in 2.5, a shift to income taxation suppresses a reduction in average lifetime income and reduces the progressivity of the system, both compared to reform II. Progressivity on an annual 
income basis also falls, because the old have to pay taxes.

Reform IV applies consumption tax with no price indexation instead of income tax to finance the benefits. In our simple model, net lifetime income (before consumption tax) is proportional to the sum of gross lifetime income and (not price-indexed) benefits. Hence, a reduction of the SCV and effective progression are the same in both reforms III and IV. This result contrasts with that on an annual basis, which shows that consumption tax is less progressive because the old have to pay more taxes than under income taxation. Meanwhile, a reduction of average lifetime income is more limited in reform IV than in reform III, suggesting that consumption tax with no price indexation is preferable to income tax.

It seems, however, to be more realistic to presume price indexation for the social security benefits when introducing consumption tax. Reform $\mathrm{V}$ attempts to do this. Consumption tax with price indexation makes average net lifetime income somewhat lower than in the case of no price indexation, but still higher than in the case of income tax. However, it makes net lifetime income more equally distributed than those two reforms, but still less than in the case of no taxation. Looking again at Figure 2, we recognize the possibility that lower income individuals can be better off net even under a PAYGO system, once the social security benefit is limited to its flat component. The introduction of consumption tax raises this possibility, because it can reduce the decrease of average net income ${ }^{16}$.

Figure 3 plots a combination of a change in average lifetime income and a reduction of the SCV reported in Table 2, to help compare each reform in terms of efficiency and intragenerational equity ${ }^{17}$. Starting with the current system as a benchmark, upward and

\footnotetext{
16 This appears to contradict the conventional view that emphasizes the regressivity of a consumption tax, considering that lower income individuals have a higher propensity to consume. In our model, all individuals spend all of their lifetime income through life, thus the propensity to consume through life is equal to one for all individuals.

17 We can draw almost the same figure if we use effective progression instead of a reduction of the SCV.
} 
rightward shifts indicate improvements of efficiency and equity, respectively. Reform I reduces inequality of income, but little improvement in average income makes it less attractive, especially compared to reforms II-V. Accordingly, removing the cap does not appear to be enough. Reforms II-V, which call for scaling down the social security benefit to only a flat component on top of removing the cap, are all preferable to the current one in terms of both efficiency and equity.

Which is the best choice? Reform III is clearly inferior to reforms IV and V as can be clearly seen in the figure, but it is difficult to compare the remaining three. Reforms IV and V are superior in terms of efficiency, whereas reforms II and V are relatively desirable in terms of equity. Taking into account a small difference in the reduction of the SCV between reforms II and $\mathrm{V}$, as well as a small difference in the reduction of average income between reforms IV and $\mathrm{V}$, and also considering that having no price indexation incorporated in reform IV is difficult in practice, reform $\mathrm{V}$ could be the most desirable and plausible choice; that is, it appears advisable for the government to finance the flat social security benefit with consumption tax and price indexation, provided it wants to maintain a PAYGO system.

Of course, this is just a rough comparison without any rigorous judgment criteria, and the relative performance of each reform depends on assumptions of economic and demographic variables. Moreover, the government has another choice: shifting to a fully funded system, which is located at the origin in Figure 3. This reform appears to improve efficiency over the current system ${ }^{18}$, but loses progressivity, suggesting that the government needs another policy measure to redistribute lifetime income within the same generation.

\section{Concluding Remarks}

${ }^{18}$ As mentioned in note 3, we ignore the need to compensate the existing pension liabilities. 
This paper investigates how a social security system redistributes lifetime income within the same generation in Japan. As is widely recognized, a PAYGO social security system reduces net lifetime income with an aging population, because it entails income transfers from the young to the old. Even on a lifetime basis, however, it may redistribute income from high-income individuals to low-income individuals due to its progressive structure. Hence, it is important to assess the intragenerational redistribution of a PAYGO social security system.

The key results of our analysis based on a simple life-cycle model and policy simulations using data from the 1996 Survey on the Redistribution of Income are summarized as follows. First, the redistributive effects and the progressivity of the current social security system are much more limited on a lifetime basis than observed on an annual basis. Also, the "incompleteness" of the system makes it difficult to capture the whole structure of its progressivity. Second, shifting to a simple system that consists of a flat benefit and a wage-proportional premium and has no contribution cap can be one of the most desirable PAYGO reforms with an aging population, because it can suppress a reduction of net lifetime income on average, as well as reduce its relative inequality within the same generation. Third, once the system is simplified, financing a price-indexed flat benefit with consumption tax appears to be a good choice in terms of both efficiency and intragenerational equity.

Our analysis, however, has several limitations and many issues remain to be addressed. Due to a lack of longitudinal information, our estimation of the redistributive effects relies heavily on data that are synthetically reorganized from cross-section data from the Survey. Heterogeneity regarding family structure, mortality, and other factors, which is totally neglected in this paper, would likely provide different pictures of income distribution, as already demonstrated by earlier research in the United States. In particular, more labor force participation by women would affect the overall progressivity of the social security system. 
Finally, our comparative statics, which focus on the policy impact on steady states and ignore the issues how to compensate for existing pension liabilities, cannot provide a comprehensive assessment of policy reforms.

\section{References}

Boskin, M. J., L. J. Kotlikoff, D. J. Puffert, and J. B. Shoven (1987) "Social Security: A financial appraisal across and within generations," National Tax Journal, Vol. 40, pp. 19-34.

Breyer, F. (1989) "On the intergenerational Pareto efficiency of pay-as-you-go financed pension systems," Journal of Institutional and Theoretical Economics, Vol. 145, pp. 643-658.

Coronado, J. L., D. Fullerton, and Th. Glass (2000) "The progressivity of social security," NBER Working Paper 7520. and (2002) "Long-run effects of social security reform on Lifetime

Progressivity," in M. Feldstein and Jeffrey B. Liebman, ed., The Distributive Aspects of Social Security and Social Security Reform, Chicago: The University of Chicago Press, pp. 149-205,

Geanakoplos, J., O. S. Mitchell and S. P. Zeldes (1998), "Would a privatized social security system pay a higher rate of return?" in D. Arnold, M.Graetz and A. Munnell, eds., Framing the Social Security Debates, Washington, D.C.: Brooking Institution, pp. 137-156.

Gustman, A. and Th. Steinmeier (2001) "How effective is redistribution under the Social Security benefit formula?" Journal of Public Economics, Vol. 82, No. 1, pp. 1-28. 
Hatta, T., N. Oguchi, and W. Sakamoto (1998). "Nenkin kaikaku to sedaikan saibunpai [Public pension reform and intergenerational redistribution]," Quarterly of Social Security Research Vol. 34, No. 2, pp. 155-164.

Liebman, Jeffrey B. (2002). "Redistribution in the current U.S. social security system," in M. Feldstein and J. B. Liebman, ed., The Distributive Aspects of Social Security and Social Security Reform, Chicago: The University of Chicago Press, pp. 11-48.

Ministry of Health, Labor, and Welfare (2002). White Paper on Health, Labor, and Welfare.

Musgrave, R.A. and T. Thin (1948). "Income Tax Progression 1929-1948," Journal of Political Economy, Vol. 56, pp. 498-514.

Nelissen, J. H. M. (1998). "Annual and lifetime income redistribution by social security," Journal of Public Economics, Vol. 68, pp.223-249.

(2000). "Lifetime income redistribution by social security," Journal of Population Economics, Vol.8, pp.89-105.

Ohtake, Fumio and Makoto Saito (1999). "Shotoku fubyodoka no haikei to sono seisakuteki gan'i [On the Income Inequity during the 1980s: Causes and implications]," Quarterly of Social Security Research, Vol. 35, No. 1, pp. 65-75.

Oshio, Takashi (2002). "Intra-age, inter-age and lifetime income redistribution," Journal of Population and Social Security, Vol. 1, No.1, pp. S36-S49

Shimono, Keiko and Toshiaki Tachibanaki (1985), "Lifetime income and public pension," Journal of Public Economics, Vol. 26, 75-87.

Sinn, Hans-Werner (2000). "Why a funded pension system is useful and why it is not useful?" NBER Working Paper 7592.

Takayama, Noriyuki et al. (1990). "Jinteki shisan no suikei to koteki nenkin no saibunpai kouka [Estimation of Human Assets and Redistributive Effects of Public Pensions]", Keizai Bunseki 118. 
and Yukinobu Kitamura (1999). "Lessons from generational accounting in Japan," American Economic Review, Vol.89, pp. 171-175.

Terui, Hroshi and Takatoshi Ito (1994). "Misekake no fubyodo to shin no fubyodo [Apparent inequalities and true inequalities: A simulation analysis using an overlapping generations model]" in Tsuneo Ishikawa ed., Nihon no Shotoku to Tomi no Bunpai [Income and Wealth Distribution in Japan], Tokyo: University of Tokyo Press, pp. 279-320. 